\title{
Development of a tool to assess core cardiorespiratory physiotherapy skills: a Delphi study.
}

ROBERTS, F. and COOPER, K. 


\section{Development of a Tool to Assess Core Cardiorespiratory}

2 Physiotherapy Skills: An e-Delphi Study.

\section{ABSTRACT}

4 Purpose: This study reports on the development of an outcome measure designed to

5 evaluate pre-registration physiotherapy students' ability in performing core

6 cardiorespiratory skills.

7 Method: A four round, e- Delphi study using an international panel of expert

8 cardiorespiratory physiotherapists involved in pre-registration student education was

9 undertaken. In round one participants identified what they look for in students competently performing core cardiorespiratory physiotherapy assessment and treatment

11 skills. These items were refined in rounds two and three. Item content validity score

12 (iCVI) of $\geq 0.8$ at round four identified consensus. Scale content validity index (SCVI)

13 was calculated. Results: Response rate for round one was $46 \%$ (6/13). Additional

14 experts were invited to participate and response rates increased to $71 \%$ (round 2), $88 \%$

15 (round 3) and 100\% (round 4). Of the 207 items across the seven skills identified in

16 round one, 140 were presented in round four. Of these, consensus was achieved for 128

17 items, with 12 being excluded. The SCVI was 0.907. Conclusion: This e-Delphi study

18 enabled the development of a draft outcome measure which aims to assess performance

19 of seven cardiorespiratory physiotherapy skills. This tool will enable rigorous

20 evaluation of different education methods to establish their effectiveness. However, it

21 is first necessary to establish construct validity and assess inter and intra-rater

22 reliability.

23 Words: 207

24 Keywords: outcome measures; education; Delphi technique; students. 
27 In their 'Perspectives' editorial, Jensen et al. (2016) discuss a 'bench-to-bedside' 28 approach to education research for health professions. This framework indicates a need 29 for: 1) basic research considering fundamental tools such as measurement, skills 30 assessment, and evaluation; 2) applied research which shows the benefits of educational 31 interventions; 3) translational research which can provide explanations about how 32 learning is occurring, and 4) systems research focusing on the complex systems involved 33 in education and health care (Jensen et al, 2016).

35 The need for robust evidence to support educational methods is supported by pressures experienced by higher education (HE) and the health service (Kings Fund 2018; Lacobucci, 2017; Mercer, 2015). Drivers to provide quality healthcare while reducing costs and addressing workforce issues are global (Deloitte, 2018) and they impact on clinical placement capacity, a critical element of physiotherapy student learning (World

40 Confederation on Physical Therapy (WCPT), 2015). Due to these pressures, it is essential to demonstrate that learning methods are effective; to use optimal methods that enable students to be appropriately prepared for placement enabling them to gain the most from their critical clinical learning (Korpi, Peltokallio, and Piirainen, 2014).

A learning method being increasingly used is simulated learning, defined as: An array of structured activities that represent actual or potential situations in education and practice. These activities allow participants to develop or enhance their knowledge, skills, and attitudes, or to analyse and respond to realistic situations in a simulated environment. (Lopreiato, 
52 Watson et al. (2012) and Blackstock et al. (2013) demonstrated that simulation can

53 replace part of clinical time with no detriment to student development and, due to the

54 work conducted by Wright, Moss, Watson, and Rue (2015), this is now an accepted part

55 of entry level curricula in Australia (Chipchase, Blackstock, Patman, and Barnett-

56 Harris, 2018). It is also used across the United Kingdom (UK), Canada, and the United

57 States of America (USA) (Melling et al, 2018). Despite a wealth of published literature

58 reporting positive student perceptions of this learning method, a recent systematic review (Roberts and Cooper, 2019) found only one pilot study reporting on the effect of high-fidelity simulation (HFS) on student skill performance. The pilot study suggested

61 that HFS may be detrimental to student skill development (Phillips, Mackintosh, Bell,

62 and Johnston, 2017). However, evidence has shown that HFS can increase student

63 stress levels. If this was students' first exposure to HFS, and specifically simulated

64 patients, high stress levels may have limited student learning and resulted in poorer skill performance (Judd et al, 2019; Sabus and Macauley, 2016).

67 To be able to effectively evaluate learning methods and their impact on students, it is

68 essential to have valid and reliable outcome measures; lack of such measures is currently a fundamental limitation to research on learning methods in physiotherapy education. A systematic review of outcome measures for procedural skills in physiotherapy education found only six measures in existence (Sattelmayer, Hilfiker, and Baer, 2017). All six are focused on musculoskeletal skills, four have established content validity, and only one has reported on inter-rater reliability. Consequently, to undertake robust research evaluating learning methods used in cardiorespiratory physiotherapy teaching, valid and reliable outcome measures must first be developed. 
77 This study therefore aimed to develop an outcome measure that enables the evaluation

78 of core clinical skills competency in cardiorespiratory physiotherapy and to establish the content validity of the outcome measure developed.

\section{METHOD}

82 The Delphi expert consensus method, a systematic method to develop and measure

83 consensus, which helps ensure content validity of an outcome measure, was employed

84 (Humphrey-Murto et al, 2016). Typically, round one is used to develop the statements

85 for subsequent rounds (up to four). Participants' views are analysed between-rounds and

86 contribute to the next round's questionnaire, enabling the views, experience and

87 knowledge of a wide range of experts to be utilised without undue influence from any

88 dominant individuals (Humphrey-Murto, Vaipo, Gonsalves, and Wood, 2017;

89 McPherson, Reese, and Wendler, 2018). Ethics approval was granted by the School of

90 Health Sciences Research Review Group (ref: SHS/17/18).

92 Participants

93 Consensus from an international group of experts is recommended for establishing

94 content, face and concurrent validity (Baker, Lovell, and Harris, 2006). The following definition of experts was used in this study:

96 - Involved in writing core cardiorespiratory physiotherapy textbooks and/or

97 - At least two recent publications ( $<10$ years) relating to cardiorespiratory

98 physiotherapy topics in peer-reviewed journals indexed in Medline or CINHAL

99 and

100 - Involved in teaching pre-registration physiotherapy students as an academic or

$101 \quad$ clinical educator and preferably with 
- Wider activity such as certified cardiorespiratory specialist, involvement in specialist cardiorespiratory physiotherapy groups, national guideline development.

106 Experts were located by: (i) searching Medline and CINHAL for articles published in

107 the last 10-years using the following terms: chest physical therapy, respiratory physical

108 therapy, chest clearance techniques, and (ii) searching author lists from core

109 cardiorespiratory textbooks. The online profiles of authors (experts) identified in this

110 way were subsequently reviewed against the criteria identified above. A population of

111 nineteen potential participants from Australia, Canada, New Zealand and the UK met

112 the pre-defined criteria.

114 Due to a low response rate in round one, a further search for experts was undertaken

115 prior to round two. This involved a search of staff databases for each university

116 providing pre-registration physiotherapy education in Australia, Canada, New Zealand

117 and the UK for participants that met the predefined criteria. This provided a further list

118 of experts not found prior to round one as their publications did not meet the specific

119 search terms used in Medline and CINHAL. However, identification of participants

120 was limited in this search by accessibility of staff profiles on university websites.

\section{$122 \underline{\text { Round } 1}$}

123 A demographic questionnaire was developed to gather data about participants'

124 academic qualifications and years qualified/ specialised in cardiorespiratory

125 physiotherapy/working with students. Participants were asked to identify the

126 assessment and treatment techniques they considered core in cardiorespiratory 
127 physiotherapy (Supplementary file 1). This also acted to indicate experts consent to

128 participate.

129

130 Round one, developed by the lead author, asked participants to detail the various aspects

131 of the skill they would expect to be demonstrated when they observed students

132 performing core cardiorespiratory assessment and treatment techniques. The skills

133 included were those identified by the initial respondents to the demographic

134 questionnaire $(n=13)$. To limit the length of the questionnaire and to encourage

135 respondents to participate, only two assessment skills and three treatment skills were

136 included. These were selected based on the number of respondents agreeing that the

137 skill was core, on 'observability' of the skill and the need for minimal equipment

138 beyond a stethoscope. Participants were asked to focus on all aspects of the skill

139 (explanations, instructions and actual performance). This involved collection of

140 qualitative data via open questions along with two closed questions detailing lists of

141 areas of the thoracic cage which could be palpated and auscultated from which

142 participants could select those they would expect to be used.

143

144 An online questionnaire was used (onlinesurvey.ac.uk) as this has been shown to

145 increase completeness of responses since they can be set up to require a response before

146 respondents progress to subsequent questions (Helms, Gardner, and McInnes, 2017).

147

148 An invitation email, including a link to the demographic questionnaire and information

149 sheet detailing the purpose of the study and requirements of participants, was sent to 19

150 potential participants in February 2018. Participants were advised that completion of

151 the demographic questionnaire would indicate consent to participate in the e-Delphi 
152 study. Reminder emails were sent two weeks after the original invitation. Those who

153 completed the demographic questionnaire were allocated a participant number to enable

154 tracking of participants, targeting of reminder emails, and exclusion of non-responders

155 from subsequent invitations. Once the demographic questionnaire was completed

156 participants were sent their participant number and the link to the Round 1

157 questionnaire.

159 Analysis Round 1

160 Frequency of responses were calculated for closed questions using an Excel $^{\circledR}$

161 spreadsheet. For the open questions, two researchers, the authors, independently

162 reviewed qualitative data to identify codes, themes, sub-themes (Cresswell, 2016).

163 These were agreed through discussion and each researcher then allocated data from all

164 responses, as appropriate, before results were compared and agreed. Both authors have

165 experience in qualitative data analysis. The lead author is a cardiorespiratory

166 physiotherapist and the other an experienced qualitative researcher with a background in

167 musculoskeletal physiotherapy. This ensured bias regarding content was avoided as

168 reviewer two would be less likely to make inferences regarding content due to less

169 developed understanding and expertise in this area.

$171 \quad$ Round 2

172 Round two clarified the various aspects of the skill required for competent skill

173 performance. Initial analysis of data in round one involved grouping the various aspects

174 of each skill identified by respondents so that similar features, for example, knowledge,

175 skill performance, communication were grouped together. From this we identified four

176 key categories: Professionalism, general patient care consideration, reasons for 
177 undertaking the skill and skill performance (potential explanation components,

178 instructions, steps involved in performing the technique, hand positions and potential

179 modifications). There were multiple items in each of these categories. Questions

180 relating to core professional and patient care items used five point Likert scales

181 (strongly agree, agree, neutral, disagree, strongly disagree) to gain agreement levels

182 with the option of providing additional clarification. Further questions required

183 participants to identify all aspects of the skills they would look for from a list of items

184 developed from round one. Free-text options were also provided for clarification of

185 responses. Sixteen new experts were identified from university websites (already

186 detailed). An invitation to participate, the same information sheet used prior to round

187 one and link to the same demographic questionnaire were sent to the potential additional

188 sixteen participants (R2+) identified between rounds 1 and 2 . Those who completed the

189 demographic questionnaire at this point $(n=8)$, along with those who had completed the

190 demographic questionnaire prior to round $1(\mathrm{R} 1)(\mathrm{n}=13)$ received the link to round 2.

191 Consequently, the questionnaire was sent to 21 potential participants.

192

193 Analysis Round 2

194 Percentage agreement (strongly agree/agree) was calculated for Likert scale questions

195 using Excel $^{\circledR}$; items that achieved $\geq 80 \%$ agreement were progressed to round three.

196 Those with $<80 \%$ agreement were rejected. Frequencies for items relating to reasons

197 for undertaking the skills and performance of each skill were calculated for items

198 identified by participants from the pre-determined list. Items identified by $>40 \%$ of

199 respondents progressed to round three and those $<40 \%$ were rejected. The same

200 reviewers independently analysed free-text comments to determine whether additional 
items identified added to current data or whether existing items should be modified in

202 line with the additional information provided. These were then discussed and agreed.

$204 \quad$ Round 3

205 The same Likert scale agreement (strongly agree - strongly disagree) was used for items

206 that were modified from round two data analysis and progressed into round three. For

207 items that were unmodified from round two, participants were asked whether they were

208 essential/nice to have/not required, to enable identification of items required for meeting

209 expectations, i.e. competence, and items that could be used to define those 'exceeding

210 expectations'. This round was sent to 16 participants comprised of: (i) the ten

211 participants recruited at round one who responded in round two, and (ii) six participants

212 from round two (the five who completed round two plus one who was unable to respond

213 at that time but indicted they wished to be involved in future rounds).

\section{Round 3 Analysis}

216 For Likert questions percentage agreement was calculated by combining strongly agree

217 and agree. Items with $\geq 80 \%$ agreement progressed to round four. Item content validity

218 index (iCVI) was calculated for other items and in line with recommendations an iCVI

$219 \geq 0.78$ were accepted as giving consensus (Polit and Beck, 2006). Items with an iCVI $\geq$

$220 \quad 0.78$ from 'essential' progressed to round four as components for 'meeting

221 expectations', that is that they are core items. Items that could identify performance

222 that 'exceeds expectations' were included in round four where an iCVI $\geq 0.78$ resulted

223 from combining 'essential' and 'nice to have'. Items not achieving an iCVI of 0.78

224 from this combination were excluded. Calculation of iCVI at this point was used to

225 enable identification of items to go forward to round 4 or be rejected. 


\section{Round 4}

228 For each technique, items identified in round three as necessary for 'meeting

229 expectations' were included. These were followed by items to identify performance

230 'exceeding expectations'. Levels of agreement were established for each item using a

231 four point Likert scale (strongly agree, agree, somewhat agree, disagree) (Polit and

232 Beck, 2006). For items considered to identify performance that was 'exceeding

233 expectations' where participants responded 'somewhat agree' or 'disagree' they had the

234 option of identifying whether the item should be included as a 'meeting expectations',

235 that is core, requirement. This avoided any potentially important items being

236 erroneously excluded.

237

238 Only 10 respondents are required to calculate iCVI (Polit and Beck, 2006). To allow

239 for non-respondents 12 round three participants were invited to complete round four.

240 To ensure equal representation, where there were more than four respondents per

241 country, an independent research assistant randomly selected four participant numbers

242 from a list (see table 1). Round four was sent out in November 2018 and closed mid-

243 December 2018.

245 Round 4 Analysis.

246 The iCVI was calculated for every item. Core items achieving an iCVI of $\geq 0.8$ were

247 included in the outcome measure. For items identified as indicating performance

248 'exceeds expectations', an iCVI of $\geq 0.8$ had to be achieved either from agreement or for

249 a combination of those who agreed and those who 'somewhat agree/disagreed' but

250 thought it should be included as 'meeting expectations'. Scale content validity index 
251 (SCVI) was calculated to assess the degree to which all items belong together in the

252 outcome measure (Polit and Beck, 2006).

253 Piloting of questionnaires

254 All questionnaires were piloted by four local cardiorespiratory physiotherapists for

255 readability prior to being distributed and minor changes were made in response to

256 feedback.

\section{$\underline{\text { RESULTS }}$}

260 Of the original 19 participants invited to participate, 13 completed the demographic

261 questionnaire and were subsequently sent the link to round one. Of these 13 only six

262 completed round one giving a response rate for round one of $46 \%(6 / 13)$. Of the 16

263 additional participants invited after round one, eight consented to participate by

264 completing the demographic questionnaire, with a response rate of $71 \%(15 / 21)$ for

265 round two. Original participants who had not replied to rounds one or two, and those

266 who had not responded to the demographic questionnaire at round two were excluded,

267 resulting in a potential sample size of 16 for round three, with a response rate of $88 \%$

268 (14/16). The response rate for round four was $100 \%(12 / 12)$. Respondents in all four

269 rounds represented Australia, Canada and the UK. Demographic data, by round, is

270 provided in table two. All respondents were involved in teaching cardiorespiratory

271 skills to students and all met the publication requirements.

272 Table 2: Demographic Data by Round

273

274

275 Round One results 
276 Three hundred and seventy two pieces of information relating to how techniques should

277 be undertaken were identified from the six respondents. Two core categories were

278 identified within the data: 1) reasons for undertaking techniques, including explanations

279 of the technique and its aims, and 2) elements of skill performance. Both reviewers

280 identified 207 specific items across the seven techniques that would progress to round 2

281 (shown in Fig 1) and a further 11 generic aspects relating to two additional categories,

282 professionalism and general patient care were also progressed.

283

284 Fig 1: Insert here

285

$286 \quad$ Round Two and Three Results

287 Seven items of professionalism and general patient care achieved $80-100 \%$ agreement

288 (table 3) in round two and could be removed until round four as further clarification was

289 not required.

290 Table 3: insert here

291

292 Round Four Results

293 In round four, 140 items were presented to the experts; 83 as potential core, 'meeting

294 expectations', items with a further 57 'exceeding expectations' items. Table 4 shows

295 the number of items included for each technique in round one, round 4 and at the

296 conclusion of round four. Four "meeting expectations" items and nine "exceeding

297 expectations" items failed to reach the iCVI of 0.8 at the end of round four (table 5) and

298 were excluded from the draft outcome measure (Supplementary file 2). In summary,

299 only one palpation point was agreed upon (lateral bases) and two auscultation points

300 (lateral and posterior bases) although six further auscultation points were agreed for 
301 'exceeding expectations' (anterior apices/mid and base, lateral mid zone, posterior

302 apice). Communication items related to feeling for movement of the chest wall,

303 listening to how the lungs sound and how the techniques would be performed/what was

304 required of the patient. For the treatment techniques, communication items related to

305 what the technique aimed to do and what was required of the patient, while skill items

306 addressed how techniques would be taught, hand positions and other relevant skill

307 items. The scale CVI (SCVI) was 0.907.

308

309 Table 4: Insert here

310

311 Table 5: insert here

312

\section{DISCUSSION}

314 This study gained consensus from a group of international cardiorespiratory

315 physiotherapy experts about the items they would expect a student to undertake to

316 demonstrate competent performance of core cardiorespiratory techniques. There was

317 agreement that the final outcome measure should include 127 items spread across the

318 seven skills which included 79 core items (professionalism items were integrated in

319 these) and 48 'exceeds expectation' items.

320

321 The first step in defining competence in a defensible and transparent way, as advocated

322 by Searle (2000), is to determine exactly what competence looks like. A review of core

323 respiratory techniques in journal articles and online resources shows a variety of

324 descriptions of the techniques and lack of clarity of exactly how students should

325 perform the techniques (Fink 2007; Lewis, Williams and Olds 2012). This limits the 
ability to objectively measure competence in skill performance, a critical element if

327 educational research is to be able to investigate the benefits of educational interventions.

328

329 As a method of establishing how well experts agree on a specific issue, a Delphi study

330 is appropriate for identifying the core elements required for competent skill

331 performance (Humphrey-Murto et al, 2016). Although there are no specific guidelines

332 relating to conducting a Delphi study, and no standard approach to data analysis,

333 general guidelines indicate the methods used in this study were appropriate

334 (McPherson, Reese, and Wendler, 2018).

335

336 The inclusion of professionalism items: consent, back care, ensuring patient

337 comfort/status and dignity are supported by a previous Delphi study, which aimed to

338 identify key professional behaviours that should be included in physiotherapy observed

339 structured clinical examinations (Blackstock et al, 2013). Blackstock et al. (2013) used

340 a panel of 10 examiners, local to the institution of the authors, involved in assessing

341 their students agreed on communication elements: explaining techniques in lay terms;

342 appropriate commands in relation to type and timing; using voice effectively and using

343 appropriate language and tone. These elements also gained consensus in this study.

344 However, respondents in this e-Delphi study were more explicit regarding specific

345 instructions and explanations that should be incorporated, resulting in an outcome

346 measure that is arguably more objective and transparent, as recommended by Searle

347 (2000). The current study also included key elements that constitute skill performance

348 in relation to teaching elements of the ACBT, as well as motor performance elements of

349 percussion and vibrations, which to our knowledge no previous tool has done. 
351 This study is further strengthened by involvement of an international panel representing

352 countries where cardiorespiratory physiotherapy is supported by special interest groups

353 (Cardiorespiratory Division, Canadian Physiotherapy Association; Association of

354 Chartered Physiotherapists in Respiratory Care, UK) and in Australia by specialist

355 status (Australian College of Physiotherapists). Clear criteria were used in defining

356 'expert status' as suggested by Jorm (2015), since previous reports on the Delphi

357 method have identified lack of clarity of 'expert status' as a weakness of the method

358 (Baker, Lovell, and Harris, 2006). Use of expert judgement is always open to

359 subjectivity and bias, although it has also been suggested that use of experts in the

360 Delphi technique ensures content and concurrent validity (Baker, Lovell, and Harris,

3612006 ; Bruce, Langley, and Tjale, 2008). Content validity is further supported by only

362 including items with iCVI of $>0.8$, with many items achieving and iCVI of 1 or 0.917 ,

363 and involving international panel members. Additionally, the Delphi technique is

364 recognised as an accurate and reliable way of consulting experts and achieving group

365 consensus (Humphrey-Murto, Vaipo, Gonsalves, and Wood, 2017).

367 The use of experts may, however, have influenced the items that achieved agreement. It

368 has been suggested that experienced practitioners develop and refine their own set of

369 rules and criteria for safe, effective practice: They critique protocols and general rules

370 governing practice, interpreting boundaries of practice according to circumstances

371 (Smith, Higgs, and Ellis, 2010). This may have led to more selectivity in items

372 determined as important; for example, only auscultation of the lateral and posterior

373 bases was agreed for competent practice. A key requirement for panel membership

374 however was involvement in student learning, either as a clinician or university

375 educator, and the wording of the questionnaires clearly stated that the study aimed to 
establish the key items required for students to demonstrate basic competence of

377 techniques. Consequently, the items included should reflect the appropriate skills for entry level practice. It may be useful to subsequently survey physiotherapists more widely about what elements they would require for these techniques so that less expert

380 views can be collated.

\section{$382 \quad \underline{\text { Limitations }}$}

383 Of the initial sample originally consenting to participate $(n=13)$ only $46 \%$ completed 384 round one. This is despite using a personalised approach and providing extensive 385 information about the purpose of the study (Helms, Gardner, and McInnes, 2017).

386 Some of the initial respondents did not have a vested interest in this area of research as

387 indicated by the three participants who declined to participate due to no longer working 388 in a suitable area of practice (Helms, Gardner, and McInnes, 2017). In round two 10 of 389 the original 13 respondents participated suggesting a further reason for the low response

390 rate may have been the nature of round one, which required approximately 30 -minutes

391 to complete. The improved response rate in subsequent rounds, where only level of

392 agreement was required (with the option of adding additional comments), and

393 consequently completion was quicker, may support this. Self-selection to participate

394 may have introduced responder bias to the results, although it is recognised practice to

395 invite people to participate in Delphi studies after defining participant characteristics

396 and for participation to be voluntary (Hsu \& Sandford 2007). It is not possible to

397 identify the degree of bias present in our results as information regarding non-

398 responders' knowledge and views was not available for analysis. However, since 10/13

399 of those initially asked to participate responded in round two the degree to which the 
three non-respondents would have influenced many of the results is questionable due to

401 the high levels

402

403 Inviting additional participants to join the study at round two may be seen as a strength

404 since the additional participants all had a clear role in providing cardiorespiratory

405 education within a higher education context as well as being published authors and

406 therefore had a clear vested interest in addition be being 'experts'. This additional

407 recruitment resulted in a response rate of $71 \%$ and this was maintained through

408 subsequent rounds (Helms, Gardner, and McInnes, 2017). This panel size and response

409 rate reflects other Delphi studies and can be considered acceptable (Forbes, Mandrusiak,

410 Smith, and Russell, 2018; Jones et al, 2017). Enabling respondents to provide

411 additional qualitative information at this stage of study, in addition to level of

412 agreement, ensured new participants could contribute fully to the content of the

413 outcome measure.

414

415 Data was collected from only English speaking countries and therefore it cannot be

416 assumed that the practices that are used across the world are reflected in this study.

417 This is a limitation if the subsequent outcome measure were to be used more widely

418 across the world. Further work would be required to investigate the skills taught more

419 widely and also what clinicians expected of students.

420

421

422 
424 This e-Delphi study has enabled the development of a draft outcome measure which

425 aims to assess skill performance of seven cardiorespiratory physiotherapy techniques;

426 two respiratory assessment skills along with five treatment techniques. This has been

427 possible through gathering consensus from a range of expert cardiorespiratory

428 physiotherapists across three countries. Development of such a tool will enable

429 rigorous evaluation of different education methods to establish their effectiveness and

430 help ensure students gain the best education possible while in the university setting.

431 Before the outcome measure can be used in research or practice however it will be

432 necessary to establish construct validity and to assess inter and intra-rater reliability.

433

434 Ethical approval: School of Health Sciences Research Review Group. Protocol

435 reference number SHS/17/18

436 Funding: This research did not receive any specific grant from funding agencies in the

437 public, commercial, or not-for-profit sectors.

438 Conflict of Interests: There are no conflicts of interests.

439

440 
442 References

443 1. Baker J, Lovell K, Harris N 2006 How expert are the experts? An exploration of the 444 concept of 'expert' within Delphi panel techniques. Nurse Researcher 14: 59-70.

2. Blackstock FC, Watson KM, Morris NR, Jones A, Wright A, McMeeken JM, Rivett DA, O'Connor V, Peterson RF, Haines TP, et al. 2013 Simulation can contribute a part of cardiorespiratory physiotherapy clinical education. Simulation in Healthcare 8: 3242.

3. Bruce JC, Langley GC, Tjale AA 2008 The use of experts and their judgements in nursing research: An overview. Curations 31: 57-61.

4. Chipchase L, Blackstock F, Patman S, Barnett-Harris A 2018 Keep the momentum going: pushing the boundaries of clinical learning and assessment. Journal of Physiotherapy 64: 205-207.

5. Cresswell JW 2016 Qualitative inquiry and research design. Choosing among five approaches $4^{\text {th }}$ Ed. Chapter 8. London, United Kingdom: Sage.

6. Deloitte 2018 Global Healthcare Outlook. The evolution of smarter healthcare. Deloitte; 2018. https:/www2.deloitte.com/content/dam/Deloitte/global/Documents/Life-SciencesHealth-Care/gx-1shc-hc-outlook-2018.pdf.

7. Fink JB, 2007 Forced Expiratory Technique, Directed Cough, and Autogenic Drainage. Respiratory Care 52: 1210-1221.

8. Forbes R, Mandrusiak A, Smith M, Russell T 2018 Identification of competencies for patient education in physiotherapy using a Delphi approach. Physiotherapy 104: 232238.

9. Helms C, Gardner A, McInnes E 2017 The use of advanced web-based survey design in Delphi research. Journal of Advanced Nursing 73: 3168-77. 

C, Foth T 2016 The use of the Delphi and other consensus group methods in medical education research: A review. Academic Medicine 92: 1491-1498.

11. Humphrey- Murto S, Vaipo L, Gonsalves C, Wood TJ 2017 Using consensus group methods such as Delphi and Nominal Group in medical education research. Medical Teacher 39: 14-19.

12. Hsu CC, Sandford BA 2007 The Delphi Technique: Making Sense of Consensus. Practical Assessment, Research and Evaluation 12(10) https://scholarworks.umass.edu/cgi/viewcontent.cgi?article=1177\&context=pare Education research in physical therapy: Vision of the Possible. Physical Therapy 96: $1874-1884$.

14. Jones A, Mandrusiak A, Judd B, Gordon C, Alison J 2017 Investigating a physiotherapy clinical simulation assessment tool using the Delphi approach. Internet Journal of Allied Health Science Practice 15(3): Article 3.

15. Jorm AF 2015 Using the Delphi expert consensus method in mental health research. Australian and New Zealand Journal of Psychiatry 49: 887-897. psychophysiological stress and confidence during high-fidelity emergency simulation: Effects on performance. Nurse Education Today 78: 44-49. Fund 2018.

18. Korpi H, Peltokallio L, Piirainen A 2014 The story models of physiotherapy students' professional development. Narrative research. European Journal of Physiotherapy 16: 219-220.

19. Lacobucci G 2017 A service under pressure. British Medical Journal 356: 16691.

20. Lewis LK, Williams MT, Olds S 2012. The active cycle of breathing technique: A systematic review and meta-analysis. Respiratory Medicine 106: 155-172. 

in Healthcare. https://www.ahrq.gov/sites/default/files/publications/files/simdictionary.pdf.

22. McPherson S, Reese C, Wendler MC 2018 Methodology Update: Delphi Studies. Nurse Researcher 67: 404-410.

23. Mercer J 2015 Making the Grade. The key issues facing the UK higher education sector. Deloitte, London. 2015.

24. Melling M, Duranai M, Pellow B, Lam B, Kim Y, Beavers L, Miller E, SwitzerMcIntyre S 2018 Simulation experiences in Canadian Physiotherapy Programs: A description of Current Practices. Physiotherapy Canada 70: 262-271.

25. Phillips AC, Mackintosh SF, Bell A, Johnston KN 2017 Developing physiotherapy student safety skills in readiness for clinical placement using standardized patients compared with peer-role play: a pilot non-randomized controlled trial. BMC Medical Education 17: 133.

26. Polit DF, Beck CT 2006 The Content Validity Index: Are you sure you know what being reported? Critique and recommendations. Research in Nursing and Health 29: 489-497.

27. Roberts F, Cooper K 2019 Effectiveness of high fidelity simulation versus low fidelity simulation on practical/clinical skill development in pre-registration physiotherapy students: a systematic review. JBI Database of Systematic Reviews and Implementation Reports. 17: 1229-1255.

28. Sabus C, Macauley K 2016 Simulation in Physical Therapy Education and Practice: Opportunities and evidence-Based Instruction to Achieve Meaningful Learning Outcomes. Journal of Physical Therapy Education 30:3-13.

29. Sattelmayer M, Hilfiker R, Baer G 2017 A Systematic Review of Assessments for Procedural Skills in Physiotherapy Education. International Journal of Health Professions 4:53-65.

30. Searl J 2000 Defining competency - the role of standard setting. Medical Education 34: 
524 31. Smith M. Higgs J, Ellis E 2010 Effect of experience on clinical decision making by cardiorespiratory physiotherapists in acute care settings. Physiotherapy Theory and Practice 26: 89-99.

32. Watson K, Wright A, Morris N, McMeeken J, Rivett D, Blackstock F, Jones A, Haines T, OConnor V, Watson G, et al. 2012 Can simulation replace part of clinical time? Two parallel randomized controlled trials. Medical Education 46: 657-667.

33. World Confederation for Physical Therapy (WCPT) 2015 Policy statement: Education. WCPT

34. Wright T, Moss P, Watson K, Rue S 2015 Simulation in Physiotherapy Clinical Training. National Simulated Learning Project. Final Report. Adelaide, Australia. Health Workforce Australia. http://lamp.physio.curtin.edu.au/simproj/HWA\%20Embedding\%20Simulation $\% 20 \mathrm{in} \%$ 20Clinical\%20Physiotherapy\%20Final\%20Report.pdf

537

538 
Table 1: Participant Flow

\begin{tabular}{|c|c|c|c|c|}
\hline Round & Sample & Responses & & Excluded \\
\hline \multirow[t]{3}{*}{ Demographic } & Participant Flow & & $13 / 19$ & $\mathrm{n}=$ \\
\hline & & & & 3 no response \\
\hline & & & & 3 declined \\
\hline Round 1 & $\mathrm{n}=13(\mathrm{R} 1)$ & $6 / 13$ & & none \\
\hline \multirow[t]{2}{*}{ Pre-round 2} & New participants & $8 / 16$ returned & & $\mathrm{n}=8$ \\
\hline & $N=16(R 2+)$ & demographics & & no response \\
\hline \multirow[t]{3}{*}{ Round 2} & $\mathrm{n}=21$ & $15 / 21$ & & \\
\hline & 13 R1 & 10/13 R1 & & 3 R1 no response \\
\hline & $8 \mathrm{R} 2+$ & $5 / 8 \mathrm{R} 2+$ & & $2 \mathrm{R} 2+$ no response* \\
\hline \multirow[t]{3}{*}{ Round 3} & $n=16$ & $14 / 16$ & & \\
\hline & 10 R1 & 9/10 R1 & & 1 R1 no response \\
\hline & $6 \mathrm{R} 2+$ & $5 / 6 \mathrm{R} 2+$ & & $1 \mathrm{R} 2+$ no response \\
\hline \multirow[t]{3}{*}{ Round 4} & $\mathrm{n}=12$ & $12 / 12$ & & \\
\hline & 9 R1 & & & \\
\hline & $3 \mathrm{R} 2+$ & & & \\
\hline
\end{tabular}

$\mathrm{R} 1=$ participants recruited for round 1

$\mathrm{R} 2+=$ participants recruited between round 1 and 2

*the remaining participant indicated they did not have time to reply to round 2 but would like to be included at round 3. 
Fig 1: Round 1 results summary

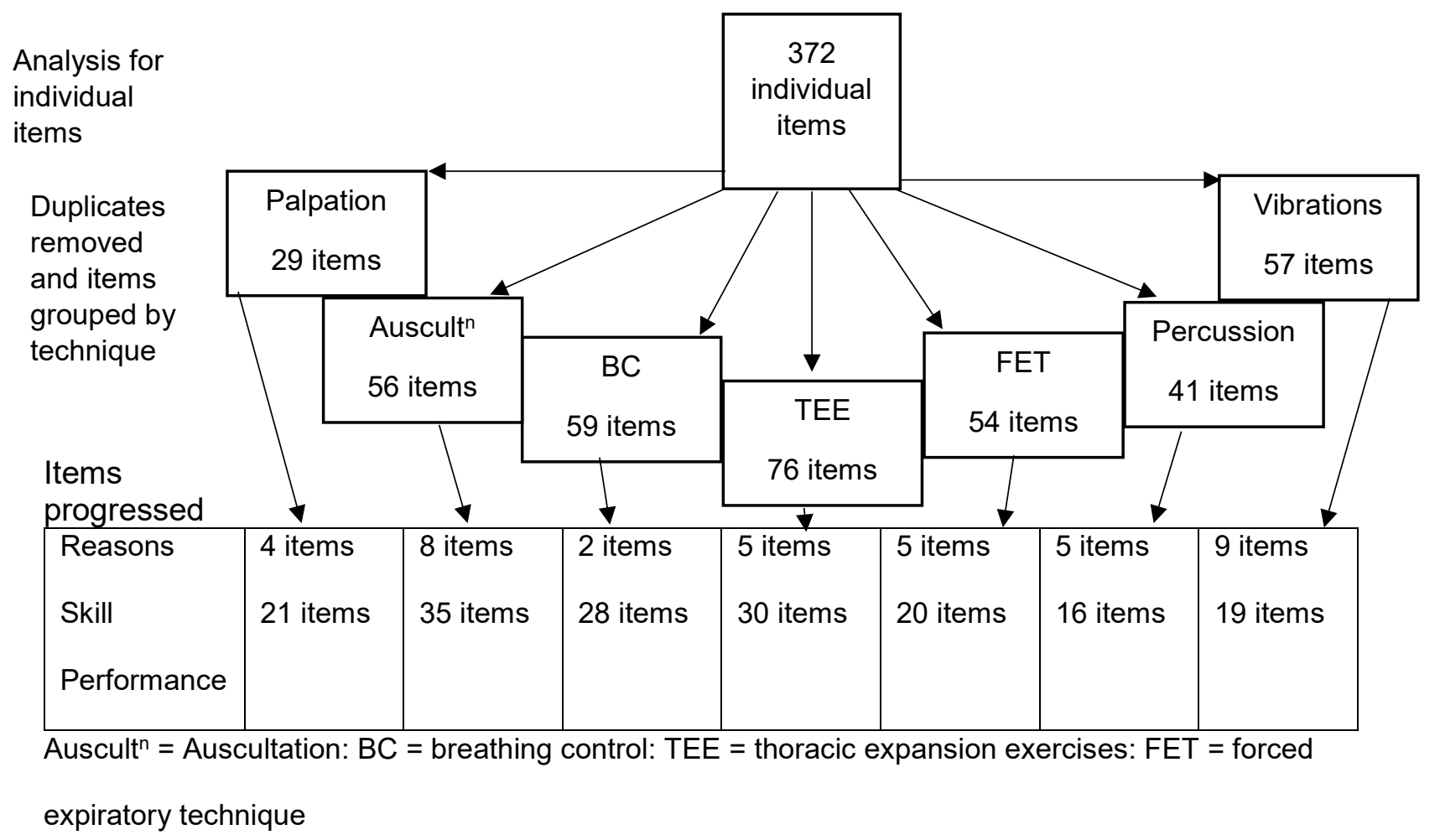


1 Table 2: Demographic Data by Round

\begin{tabular}{|c|c|c|c|c|c|}
\hline \multicolumn{2}{|c|}{ 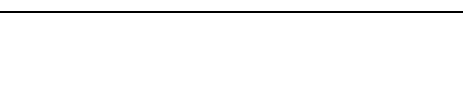 } & Round 1 & Round 2 & Round 3 & Round 4 \\
\hline \multicolumn{2}{|c|}{ Participants } & $6 / 13(46 \%)$ & $15 / 21(71 \%)$ & $14 / 16(88 \%)$ & $\begin{array}{l}12 / 12 \\
(100 \%)\end{array}$ \\
\hline \multicolumn{2}{|c|}{ Country: Australia } & $3 / 3(100 \%)$ & $6 / 12(50 \%)$ & $7 / 8(88 \%)$ & $5 / 5(100 \%)$ \\
\hline \multicolumn{2}{|l|}{ Canada } & $2 / 3(67 \%)$ & $3 / 5(60 \%)$ & $3 / 3(100 \%)$ & $3 / 3(100 \%)$ \\
\hline \multicolumn{2}{|c|}{ New Zealand } & $0 / 1(0 \%)$ & $0 / 1(0 \%)$ & - & - \\
\hline \multicolumn{2}{|l|}{ UK } & $2 / 6(33 \%)$ & $5 / 11(45 \%)$ & $4 / 5(80 \%)$ & $4 / 4(100 \%)$ \\
\hline \multicolumn{2}{|c|}{ Years Qualified } & $26.67+/-7.20$ & $26.17+/-7.36$ & $25.75+/-7.45$ & $26.17+/-7.09$ \\
\hline \multicolumn{2}{|c|}{ Mean(SD), range } & $13-32$ & $13-36$ & $13-36$ & $13-36$ \\
\hline \multicolumn{2}{|c|}{ Year in clinical practice } & $25.33+/-6.65$ & $21.4+/-9.39$ & $22.43+/-8.82$ & $23.5+/-7.82$ \\
\hline \multicolumn{2}{|c|}{ Mean(SD), range } & $13-32$ & $5-35$ & $5-35$ & $11-35$ \\
\hline \multicolumn{2}{|c|}{ Year in academia } & $12.6+/-10.11$ & $12.25+/-9.35$ & $11.5+/-9.28$ & $11.58+/-9.69$ \\
\hline \multicolumn{2}{|c|}{ Mean(SD), range } & $3-28$ & $1-28$ & $1-28$ & $1-28$ \\
\hline \multicolumn{2}{|c|}{ Years Specialized in CR } & $23.4+/-7.92$ & $20.42+/-9.07$ & $21.71+/-8.14$ & $22.30+/-8.64$ \\
\hline \multicolumn{2}{|c|}{ Mean(SD), range } & $10-30$ & $5-32$ & $10-32$ & $10-32$ \\
\hline \multirow{3}{*}{\multicolumn{2}{|c|}{$\begin{array}{l}\text { Year working with } \\
\text { students Mean(SD), range }\end{array}$}} & $23.83+/-$ & $20.23+/-9.86$ & $20.12+/-$ & $20.67+/-10.68$ \\
\hline & & 6.37 & $4-34$ & 10.22 & $4-34$ \\
\hline & & $13-32$ & & $4-34$ & \\
\hline Role & Lecturer & 3 & 10 & 9 & 8 \\
\hline with & Clinical & 2 & 1 & 1 & 1 \\
\hline students & Educator & & & & \\
\hline
\end{tabular}




\begin{tabular}{|c|c|c|c|c|}
\hline \multicolumn{5}{|c|}{ lectured/clinical } \\
\hline Other & 0 & $\begin{array}{l}1 \text { coordinator } \\
\text { student } \\
\text { program }\end{array}$ & $\begin{array}{l}1 \text { coordinator } \\
\text { student } \\
\text { program }\end{array}$ & 0 \\
\hline \multicolumn{2}{|l|}{ Highest Academic } & $9 \mathrm{PhD}$ & $9 \mathrm{PhD}$ & $7 \mathrm{PhD}$ \\
\hline \multirow{2}{*}{\multicolumn{2}{|c|}{ Qualification }} & $2 \mathrm{Ed} \mathrm{D}$ & $1 \mathrm{Ed} \mathrm{D}$ & $1 \mathrm{Ed} \mathrm{D}$ \\
\hline & & 4 Masters & 4 Masters & 4 Masters \\
\hline
\end{tabular}

2 Clinical educator= clinician supervising students in clinical practice.

$3 \mathrm{SD}=$ standard deviation

$4 \quad \mathrm{PhD}=$ Doctor of Philosophy

$5 \quad \mathrm{EdD}=$ Doctor of Education

6 
Table 3: Round 2 - Professionalism and General Patient Care

\begin{tabular}{ll}
\hline Items & Level of agreement \\
\hline 1. Consent should be gained before each technique & $93 \%$ BC and \\
& Vibrations \\
& $100 \%$ all others \\
\hline 2. Ensure own back care & $100 \%$ \\
\hline 3. Position self to avoid invading patients personal space & $80 \%$ \\
\hline 4. Avoid using jargon & $100 \%$ \\
\hline 5. Student should overtly ask the patient how they are during each & $93 \%$ \\
\hline & \\
\hline
\end{tabular}

6. Patients should be reminded before each technique to advise the student if they experience dizziness, $\quad 87 \%$ thoracic/chest pain, $\quad 93 \%$ $\begin{array}{ll}\text { increased breathlessness } & 93 \%\end{array}$ distress of any type $\quad 93 \%$

7. Students should consider the optimal position for the patient for $100 \%$ each technique

$\mathrm{BC}=$ breathing control 
Table 4: Comparison of number of items included at round 1, round 4 and agreed in round 4.

\begin{tabular}{lcccccccc}
\hline & Palp $^{\mathrm{n}}$ & Ausc $^{\mathrm{n}}$ & BC & TEE & FET & Perc $^{\mathrm{n}}$ & Vib $^{\mathrm{n}}$ & Total \\
\hline Round 1 & 25 & 43 & 30 & 35 & 25 & 21 & 28 & 207 \\
\hline Round 4 & 16 & 28 & 21 & 9 & 12 & 9 & 13 & 140 \\
$($ EE) & $(5)$ & $(12)$ & $(8)$ & $(10)$ & $(8)$ & $(4)$ & $(10)$ & $(57)$ \\
\hline Retained after R4 & 9 & 15 & 12 & 9 & 12 & 9 & 13 & 127 \\
(EE) & $(3)$ & $(10)$ & $(5)$ & $(9)$ & $(8)$ & $(3)$ & $(10)$ & $(48)$
\end{tabular}

$\overline{\mathrm{EE}}=$ Exceeds Expectation; $\mathrm{R} 4=$ round $4 ; \mathrm{Palp}^{\mathrm{n}}=$ palpation; $\mathrm{Ausc}^{\mathrm{n}}=$ auscultation; $\mathrm{BC}=$ breathing control; TEE = thoracic expansion exercises; FET = forced expiratory technique; $\operatorname{Perc}^{\mathrm{n}}=$ percussion' $\mathrm{Vib}^{\mathrm{n}}=$ vibrations. 
Table 5: Round 4 Excluded Items

\begin{tabular}{lc}
\hline Item & iCVI \\
\hline Palpation: Explains feeling for symmetry of movement & 0.667 \\
\hline Palpation: Palpates anterior apices & 0.583 \\
\hline Palpation: Palpates posterior bases & 0.5 \\
\hline Palpation: Overtly asks the patient about their status & 0.75 \\
\hline Auscultation: I would expect the student to clean their stethoscope in the & 0.633 \\
\hline & \\
\hline & \\
\hline presence of the patient & 0.633 \\
\hline
\end{tabular}

Auscultation position: posterior mid zones

0.75

\begin{tabular}{ll}
\hline BC: hand placed on the patients abdomen below sternum but above umbilicus & 0.75
\end{tabular}

BC: Encourages patient to allow abdominal wall to move forward with each $\quad 0.633$ breath

$\mathrm{BC}$ : encourages patient not to worry about the rate or depth of breathing $\quad 0.633$

\begin{tabular}{ll}
\hline BC: stands close to the patient & 0.75
\end{tabular}

TEE: uses sniffs at maximal inspiratory hold as appropriate if relevant for $\quad 0.633$ patients presentation

Percussion: technique applied for between 30 secs -2 mins $\quad 0.667$

Key: $\mathrm{BC}=$ breathing control; $\mathrm{TEE}=$ thoracic expansion exercises 
Supplemental Data 2: Round 4 Results

\begin{tabular}{|l|l|}
\hline 1: Palpation Statements & iCVI \\
\hline 1.1 Explains feeling for movement/ expansion of chest wall & 1 \\
\hline 1.2 Explains feeling for symmetry of movement & 0.633 \\
\hline 1.3 Consent gained & 1 \\
\hline 1.4 Patient is optimally positioned & 1 \\
\hline $\begin{array}{l}\text { 1.5 Explains they will place their hands on different areas of the patients thoracic } \\
\text { cage }\end{array}$ & 0.917 \\
\hline $\begin{array}{l}\text { 1.6 Advises the patient they should breath normally and with big breaths when } \\
\text { requested }\end{array}$ & 1 \\
\hline $\begin{array}{l}\text { 1.7 Advises patient to let the student know if they experience pain/light } \\
\text { headedness of dizziness/ discomfort }\end{array}$ & 0.917 \\
\hline 1.8 Palpates lateral bases & 0.833 \\
\hline 1.9 Positions self for back care & 0.917 \\
\hline 1.10 Avoids using jargon or clarifies jargon & 0.833 \\
\hline 1.11 Overtly asks the patient about their status ie if they are OK & 0.75 \\
\hline $\begin{array}{l}\text { 1.1EE Explains palpation to help identify where there may be problems in the } \\
\text { patients lungs that physio may help with }\end{array}$ & 0.833 \\
\hline 1.2EE Explain they will palpate through inspiration and expiration & 0.833 \\
\hline 1.3EE Advise the patient they will palpate for several breaths & 1 \\
\hline 1.4EE Palpate anterior apices & 0.633 \\
\hline 1.5EE Palpate posterior bases & 0.633 \\
\hline
\end{tabular}




\begin{tabular}{|l|l|}
\hline 2: Auscultation Statements & iCVI \\
\hline $\begin{array}{l}\text { 2.1 explains listening to the sounds that the airways and lungs make when you } \\
\text { breath }\end{array}$ & 0.917 \\
\hline 2.2 Gains consent for auscultation & 1 \\
\hline 2.3 Stethoscope applied directly on skin & 0.917 \\
\hline 2.4 Advises the patient to breath in and out through an open mouth & 0.917 \\
\hline 2.5 Appropriately positions or repositions patient for auscultation & 0.917 \\
\hline $\begin{array}{l}\text { 2.6 Advises patient to let the student know if they experience pain/light } \\
\text { headedness of dizziness/discomfort }\end{array}$ & 0.917 \\
\hline 2.7 Patient reminded about depth of breath if necessary & 0.917 \\
\hline 2.8 Patient dignity/comfort considered using towels/draping & 0.917 \\
\hline 2.9 Auscultates lateral bases & 0.833 \\
\hline 2.10 Auscultates posterior mid zone & 0.75 \\
\hline 2.11 Auscultates posterior base & 1 \\
\hline 2.12 Listens throughout the respiratory cycle at each auscultation point & 1 \\
\hline 2.13 Overtly asks the patient about their status ie if they are OK & 0.833 \\
\hline 2.14 positions self to ensure back care & 0.917 \\
\hline $\begin{array}{l}\text { 2.15 positions self with consideration of patients personal space throughout } \\
\text { intervention }\end{array}$ & 0.917 \\
\hline 2.16 Avoids using jargon or clarifies jargon & 0.833 \\
\hline $\begin{array}{l}\text { 2.1EE I would expect the student to clean their stethoscope in the presence of the } \\
\text { patient }\end{array}$ & 0.633 \\
\hline $\begin{array}{l}\text { 2.2EE Explains auscultation gives insight into how breathing/lungs sound and } \\
\text { compare to normal }\end{array}$ & 0.833 \\
\hline $\begin{array}{l}\text { 2.3EE Explains auscultation determines if there are any problems that physio can } \\
\text { help }\end{array}$ & 0.633 \\
\hline 2.4EE Explicit conversation of how therapist is to navigate/manage breast tissue & 0.833 \\
\hline 2.5EE Patient asked to take normal, comfortable breaths then for deep breaths & 1 \\
\hline 2.6EE Right to left, left to right technique used to compare sides & 1 \\
\hline 2.7EE Auscultates anterior apices & 1 \\
\hline 2.8EE Auscultates anterior mid zones & 0.917 \\
\hline 2.9EE Auscultates anterior right base & 0.917 \\
\hline 2.10EE Auscultates lateral mid zone & 0.917 \\
\hline 2.11EE Auscultates posterior apice & 0.917 \\
\hline 2.12EE Explains what was heard and what it means for treatment to patient & 0.917 \\
\hline
\end{tabular}




\begin{tabular}{|l|l|}
\hline 3: Breathing Control Statements & iCVI \\
\hline $\begin{array}{l}\text { 3.1 Explains BC aims to help relax the patient, focus attention on quiet breathing, } \\
\text { rib cage movement and relaxed airflow }\end{array}$ & 1 \\
\hline $\begin{array}{l}\text { 3.2 Advises patient to let the student know if they experience pain/light } \\
\text { headedness of dizziness/discomfort }\end{array}$ & 1 \\
\hline 3.3 Ensures the patient is in a comfortable, supported position & 1 \\
\hline 3.4 Consent to place hand on patients abdomen & 0.917 \\
\hline 3.5 hand placed on patients abdomen, below the sternum but above the umbilicus & 0.833 \\
\hline 3.6 Patient encouraged to breath in a manner that is comfortable for them & 1 \\
\hline 3.7 Performs active listening during the technique & 0.917 \\
\hline 3.8 Uses a soft tone to encourage maximal relaxation and control & 1 \\
\hline 3.9 Instructions succinct and kept to a minimum & 1 \\
\hline 3.10 Positions self to ensure back care & 0.917 \\
\hline 3.11 Positions self with consideration of the patients personal space & 0.917 \\
\hline 3.12 Avoids using jargon or clarifies jargon & 0.917 \\
\hline 3.13 Overtly asks the patient about their status ie if they are OK & 0.833 \\
\hline $\begin{array}{l}\text { 3.1EE Encourages patient to focus efforts to breath gently/quietly, relax in lower } \\
\text { chest }\end{array}$ & 1 \\
\hline $\begin{array}{l}\text { 3.2EE Encourages patient to allow their abdominal wall to move forward with } \\
\text { each breath }\end{array}$ & 0.633 \\
\hline 3.3EE Encourages patient to relax their shoulders on expiration & 0.833 \\
\hline $\begin{array}{l}\text { 3.4EE Encourages patient to minimize effort and upper chest/accessory muscle } \\
\text { activity }\end{array}$ & 1 \\
\hline 3.5EE Encourages patient not to worry about rate or depth of breathing & 0.633 \\
\hline $\begin{array}{l}\text { 3.6EE Encourages patient to focus attention on breathing and where movement is } \\
\text { occurring }\end{array}$ & 0.833 \\
\hline 3.7EE Stands close to patient & 0.75 \\
\hline $\begin{array}{l}\text { 3.8EE If patient struggles with BC considers other hand positions eg hand on } \\
\text { sternum + abdomen or hand on upper trapezius }\end{array}$ & 0.833 \\
\hline
\end{tabular}




\begin{tabular}{|l|l|}
\hline 4: Thoracic Expansion Exercises Statements & iCVI \\
\hline 4.1 Explains TEE used to prevent or treat reduced lung volume & 1 \\
\hline 4.2 patient positioned/repositioned appropriately to their needs & 1 \\
\hline 4.3 Consent gained to place hands on thoracic wall & 1 \\
\hline 4.4 Patient asked to focus on increasing depth of the breath in ie maximal breath & 1 \\
\hline $\begin{array}{l}\text { 4.5 Explains inspiration should be slow and comfortable rather than short and } \\
\text { sharp }\end{array}$ & 0.917 \\
\hline $\begin{array}{l}\text { 4.6 Reminds patient to let the student know if they experience pain/light } \\
\text { headedness of dizziness/discomfort }\end{array}$ & 1 \\
\hline 4.7 Positions self to ensure back care & 0.917 \\
\hline 4.8 Avoids jargon or clarifies jargon & 0.833 \\
\hline 4.9 Overtly asks the patient about their status ie if they are OK & 0.833 \\
\hline $\begin{array}{l}\text { 4.1EE Explains TEE are used to prevent lung complications post-surgery (when } \\
\text { appropriate) }\end{array}$ & 0.833 \\
\hline 4.2EE Explains TEE are used to move secretions (when appropriate) & 0.917 \\
\hline 4.3EE Encourages patient to try to keep shoulders and neck relaxed & 1 \\
\hline 4.4EE Performs sets of 3-4 breaths & 1 \\
\hline $\begin{array}{l}\text { 4.5EE Appropriately positions hands with palms on lateral chest wall between } \\
\text { ribs 6-10 }\end{array}$ & 0.833 \\
\hline 4.6EE Provides proprioceptive input from hands on chest to provide feedback & 0.917 \\
\hline 4.7EE Provides encouragement/feedback on depth of breath (aiming for TLC) & 1 \\
\hline $\begin{array}{l}\text { 4.8EE Provides encouragement/feedback on speed/flow (not fast gulping air but } \\
\text { slow controlled basal expansion) }\end{array}$ & 0.833 \\
\hline 4.9EE Uses sustained maximal holds/inspiratory hold as appropriate & 1 \\
\hline 4.10EE Uses sniffs at maximal inspiratory hold as appropriate & 0.633 \\
\hline
\end{tabular}




\begin{tabular}{|l|l|}
\hline 5: Forced Expiratory Technique Statements & iCVI \\
\hline $\begin{array}{l}\text { 5.1 Explains FET is a forced expiratory effort designed to increase airflow within } \\
\text { the airways and help move secretions to the mouth }\end{array}$ & 0.917 \\
\hline 5.2 Instructs the patient to force air out through an open mouth & 1 \\
\hline $\begin{array}{l}\text { 5.3 Reminds patient to let the student know if they experience pain/light } \\
\text { headedness of dizziness/discomfort }\end{array}$ & 0.833 \\
\hline 5.4 Consent gained to try technique & 1 \\
\hline 5.5 Provides verbal explanation and demonstration & 1 \\
\hline 5.6 Provides feedback/guidance about volume of inspiration & 0.917 \\
\hline 5.7 Provides feedback about the force and duration of expiratory phase & 0.917 \\
\hline 5.8 Feedback, as required, about keeping mouth and glottis open & 1 \\
\hline 5.9 Avoids using jargon or clarifies jargon & 0.917 \\
\hline 5.10 Positions self with consideration of patients person space & 0.917 \\
\hline 5.11 Positions self to ensure back care & 0.917 \\
\hline 5.12 overtly asks the patient about their status ie if they are OK & 0.833 \\
\hline 5.1EE Explains will move secretions from further out than a cough & 0.917 \\
\hline 5.2EE Explains 3 different volumes of breath may be used, small/medium/large & 0.833 \\
\hline 5.3EE If relevant explains FET can be less painful than a cough & 1 \\
\hline $\begin{array}{l}\text { 5.4EE Explains the approach of low to mid to large volume hugs depending on } \\
\text { when secretions heard on expiration }\end{array}$ & 1 \\
\hline 5.5EE Ensures slow, relaxed inspiration to desired lung volume & 0.917 \\
\hline 5.6EE requires patient to keep back of throat open & 0.917 \\
\hline 5.7EE Emphasises patient needs to use a short sharp huff out & 0.833 \\
\hline 5.8EE Explains like fogging up a mirror & 0.917 \\
\hline
\end{tabular}

\begin{tabular}{|l|l|}
\hline 6: Percussion Statements & $\mathrm{iCVI}$ \\
\hline $\begin{array}{l}\text { 6.1 Explains it is rhythmical clapping of the chest wall applied by a cupped hand } \\
\text { through towel }\end{array}$ & 0.917 \\
\hline 6.2 Consent to perform technique & 0.917 \\
\hline $\begin{array}{l}\text { 6.3 Reminds patient to let the student know if they experience pain/light } \\
\text { headedness of dizziness/discomfort }\end{array}$ & 0.917 \\
\hline 6.4 Positions/repositions appropriate to their needs for sputum drainage & 0.917 \\
\hline 6.5 Appropriate layer of towel/padding over chest area to be percussed & 0.833 \\
\hline 6.6 Hand cupped to generate hollow sound & 0.917 \\
\hline 6.7 Positions self to ensure back care & 0.917 \\
\hline 6.8 Positions self with consideration of patients personal space & 0.833 \\
\hline 6.9 Overtly asks the patient about their status ie if they are OK & 0.917 \\
\hline $\begin{array}{l}\text { 6.1EE Explains the rhythmical force wave may assist the movement of secretions } \\
\text { towards the mouth where it can be expectorated }\end{array}$ & 0.833 \\
\hline 6.2EE Ensures relaxed write but firm hand & 0.833 \\
\hline 6.3EE Uses rhythmical rate & 0.833 \\
\hline 6.4EE Technique applied for between 30sec-2mins & 0.75 \\
\hline
\end{tabular}




\begin{tabular}{|l|l|}
\hline 7: Vibration Statements & iCVI \\
\hline $\begin{array}{l}\text { 7.1 Explains vibrations move secretions to larger airways and make it easier to } \\
\text { cough up }\end{array}$ & 1 \\
\hline 7.2 Consent to perform technique & 1 \\
\hline $\begin{array}{l}\text { 7.3 Reminds patient to let the student know if they experience pain/light } \\
\text { headedness of dizziness/discomfort }\end{array}$ & 1 \\
\hline 7.4 Explains they will place their hands on patients ribs over the secretions & 0.917 \\
\hline $\begin{array}{l}\text { 7.5 Advises patient they will perform small oscillations on expiration while also } \\
\text { gently compressing chest wall with their hands }\end{array}$ & 1 \\
\hline 7.6 Applies compression to chest wall & 1 \\
\hline 7.7 Applies vibration on expiration & 1 \\
\hline 7.8 Ensures bed height low enough to allow use of body weight not arms & 1 \\
\hline $\begin{array}{l}\text { 7.9 Optimises wrist position and ability to maintain technique for required } \\
\text { duration }\end{array}$ & 0.917 \\
\hline 7.10 Avoids using jargon or clarifies jargon & 0.917 \\
\hline 7.11 Positions self to ensure back care & 1 \\
\hline 7.12 Positions self with consideration of patients personal space & 0.917 \\
\hline 7.13 Overtly asks the patient about their status ie if they are OK & 0.917 \\
\hline 7.1EE Explains vibration will help dislodge and mobilize secretions & 1 \\
\hline $\begin{array}{l}\text { 7.2EE Explains vibration moves secretions to larger airways and makes it easier } \\
\text { to expectorate }\end{array}$ & 1 \\
\hline 7.3EE Advise the vibrations may cause the patient to cough & 1 \\
\hline 7.4EE Should give warning that vibrations will be applied & 1 \\
\hline 7.5EE Applies even pressure through both hands & 1 \\
\hline 7.6EE Uses small, high frequency oscillations & 1 \\
\hline 7.7EE Ensures hands on skin and not skin rubbing & 1 \\
\hline $\begin{array}{l}\text { 7.8EE Applies adequate expiratory overpressure intensity to increase expiratory } \\
\text { flow }\end{array}$ & 0.833 \\
\hline 7.9 EE Ensures pressure is applied at the start of expiration & 0.833 \\
\hline $\begin{array}{l}\text { 7.10EE Ensures close observation and modification of technique for fatigue and } \\
\text { discomfort of joints }\end{array}$ & 1 \\
\hline EE Exceeds expectations & \\
\hline
\end{tabular}

$\mathrm{EE}=$ Exceeds expectations 